\title{
CAULE DECOMPOSTO DE BABAÇU (Attlea speciosa Mart.) COMO SUBSTRATO PARA PRODUÇÃO DE MUDAS DE MELANCIEIRA
}

\author{
Hosana Aguiar Freitas de Andrade ${ }^{1 *}$, Nayron Alves Costa ${ }^{1}$, Kleber Veras Cordeiro ${ }^{1}$, Edson \\ Dias de Oliveira Neto ${ }^{1}$, Francisca Gislene Albano ${ }^{2}$, Raissa Rachel Salustriano da Silva- \\ Matos $^{3}$
}

\footnotetext{
${ }^{1}$ Graduandos em Agronomia, do Centro de Ciências Agrárias e Ambientais da Universidade Federal do Maranhão, Chapadinha - MA. E-mail: hosana_f.andrade@ hotmail.com

${ }^{2}$ Doutora em Agronomia, Professora do Curso de Agronomia, do Centro de Ciências Agrárias e Ambientais da Universidade Federal do Maranhão, Chapadinha - MA.

${ }^{3}$ Doutoranda do Programa de Pós-graduação em Fitotecnia, da Universidade Federal do Ceará, Fortaleza - CE.
}

RESUMO: No sistema de produção de plantas, incluindo a melancia, o substrato tem importância considerada no desenvolvimento de mudas, que vai influenciar não só na germinação, mas em um aumento considerável na produção. Por esta razão com o presente trabalho objetivou-se avaliar a utilização do caule decomposto de babaçu como substrato na produção de mudas de melancieira, cultivar 'Crimson Sweet'. O experimento foi conduzido no Centro de Ciências Agrárias e Ambientais (CCAA), da Universidade Federal do Maranhão (UFMA). Foi adotado um delineamento inteiramente casualizado, com seis tratamentos de substratos a base de caule decomposto de babaçu (CDB), nas seguintes proporções: T1- 100\% de substrato comercial; T2- 20\% de CDB + 80\% de Solo; T3- 40\% de CDB + 60\% de Solo; T4- 60\% de CDB + 40\% de Solo; T5- $80 \%$ de CDB + 20\% de Solo; T6- $100 \%$ de CDB, foram realizadas quatro repetições, com 12 mudas por parcela. Não foi averiguado efeito significativo para o porcentual de emergência, índice de velocidade de emergência, índice de qualidade de Dickson, volume e massa seca do sistema radicular, enquanto para o número de folhas, altura da planta, diâmetro do caule, massa seca da parte aérea e comprimento radicular, registrou-se diferença significativa entre as diferentes composições de CDB e o substrato comercial. O caule decomposto com $100 \%$ de babaçu apresentou resultados semelhantes ao substrato comercial, e portanto, pode ser utilizado como substrato para a produção de mudas de melancieira, em função do ótimo desempenho das mudas, fácil obtenção e baixo custo.

Palavras-chave: Citrullus lanatus. Qualidade de muda. Substratos regionais.

\section{STALK DECOMPOSED BABASSU (Attalea speciosa Mart.) AS A SUBSTRATE FOR PRODUCTION OF WATERMELON SEEDLINGS}

\begin{abstract}
In the system of production of plants, including watermelon, the substrate is considered in the development of seedlings, which will influence not only germination but a considerable increase in production. For this reason, the objective of this work was to evaluate the use of the babassu decomposed stem as a substrate in the production of melancholy seedlings, 'Crimson Sweet' cultivar. The experiment was conducted at the Center of Agrarian
\end{abstract}

Cultura Agronômica, Ilha Solteira, v.26, n.3, p.406-416, 2017 
and Environmental Sciences (CCAA), Federal University of Maranhão (UFMA). A completely randomized design was used, with six treatments of substrates based on babassu decomposed stalk (CBD), in the following proportions: T1- 100\% commercial substrate; T2$20 \%$ CDB + 80\% Soil; T3- 40\% CDB + 60\% Soil; T4- 60\% CDB + 40\% Soil; T5- 80\% CDB + 20\% Soil; T6- 100\% of CBD, four replications were performed, with 12 seedlings per plot. It was not found significant effect for the emergency percentage, emergency speed index, quality index of Dickson volume and dry mass of the root system, while for the number of leaves, plant height, stem diameter, shoot dry mass and root length, there was a significant difference between the different compositions of CBD and the commercial substrate. The stalk decomposed with $100 \%$ of babassu presented similar results to the commercial substrate, and therefore, can be used as substrate for the production of watermelon seedlings, due to the optimal performance of the seedlings, easy to obtain and low cost.

Key words: Citrullus lanatus. Quality of seedling. Regional substrates.

\section{INTRODUÇÃO}

A melancia (Citrullus lanatus) ocupa lugar de destaque entre as principais olerícolas produzidas e consumidas no Brasil, por ser cultura de fácil manejo e apresentar baixo custo de produção, sendo explorada principalmente por pequenos agricultores (ROCHA, 2010). Segundo dados do Instituto Brasileiro de Geografia e Estatística (IBGE, 2014), a produção de melancia no Brasil foi de 2.171.288 toneladas, enquanto a região nordeste foi responsável por mais de $28 \%$ da produção nacional.

Conforme Maggioni et al. (2014), o desempenho da planta depende de uma fase do processo produtivo de vital importância para o êxito da exploração agrícola, que é a formação de muda. Para a produção de mudas de qualidade é necessário fornecer à planta condições adequadas para o seu desenvolvimento, condições estas de nutrição, ambiência e suporte físico para o desenvolvimento da estrutura radicular (OLIVEIRA et al., 2015). Em que de acordo com Dutra et al. (2012), entende-se que o substrato tem importância considerada no desenvolvimento de mudas, bem como, no crescimento das mesmas, incluindo, a melancia.

Assim faz-se necessário o amplo conhecimento da biodiversidade regional para buscar alternativas que venham a diminuir cada vez mais o custo da etapa de produção de mudas (COÊLHO et al., 2013). Dentre os materiais que têm potencial para composição de substratos hortícolas destaca-se o caule decomposto da palmeira de babaçu (Attalea speciosa Mart.), que é originário das regiões norte e nordeste do Brasil.

Por esta razão com o presente trabalho objetivou-se avaliar a utilização do caule decomposto de babaçu como substrato na produção de mudas de melancieira, cultivar 'Crimson Sweet'.

Cultura Agronômica, Ilha Solteira, v.26, n.3, p.406-416, 2017 


\section{MATERIAL E MÉTODOS}

O experimento de mudas de melancia (Citrullus lanatus) cv. Crimson Sweet, produzidos com substratos a base de caule decomposto de babaçu (Attalea speciosa Mart.) foi conduzido entre os meses de junho e julho de 2016, em casa de vegetação no Centro de Ciências agrárias e Ambientais (CCAA) da Universidade Federal do Maranhão (UFMA),

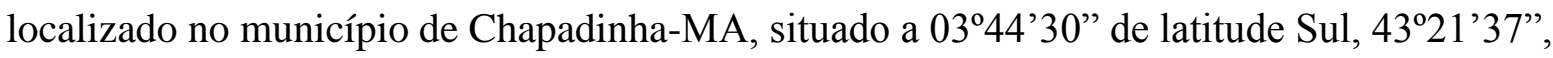
de longitude Oeste e altitude média de $107 \mathrm{~m}$. O município de Chapadinha pertence à região do cerrado maranhense com clima quente e úmido classificado por Köppen como Aw.

Foi adotado um delineamento inteiramente casualizado, com seis tratamentos, no quais os substratos foram compostos a base de caule decomposto de babaçu (CDB) e substrato comercial (Basaplant ${ }^{\circledR}$ ), as seguintes proporções: T1- 100\% de substrato comercial; T2- 20\% de CDB + 80\% de Solo; T3- 40\% de CDB + 60\% de Solo; T4- 60\% de CDB + 40\% de Solo; T5- $80 \%$ de CDB + 20\% de Solo; T6- $100 \%$ de CDB, o trabalho foi conduzido com 4 repetições, onde cada parcela continha 12 mudas, totalizando 288 mudas.

Utilizou-se bandeja de 128 células e as sementes foram semeadas a $1,5 \mathrm{~cm}$ de profundidade. Cada célula recebeu duas sementes comerciais de melancia (cultivar Crimson Sweet), após a emergência foi realizado um desbaste mantendo apenas a plântula mais vigorosa, foram realizadas duas irrigações diárias.

Tabela 1. Valores de $\mathrm{pH}$, condutividade elétrica $(\mathrm{CE})$ e teores totais de nitrogênio $(\mathrm{N})$, fósforo $(\mathrm{P})$, potássio $(\mathrm{K})$, cálcio $(\mathrm{Ca})$, magnésio $(\mathrm{Mg})$ e enxofre $(\mathrm{S})$, do substrato comercial e dos substratos a base de caule decomposto de babaçu (CDB).

\begin{tabular}{|c|c|c|c|c|c|c|c|c|}
\hline \multirow[t]{2}{*}{ Substratos } & \multirow[t]{2}{*}{$\mathrm{pH}$} & \multirow{2}{*}{$\begin{array}{c}C E \\
\mathrm{dS} \mathrm{m}^{-1}\end{array}$} & \multirow{2}{*}{$\begin{array}{c}\mathrm{N} \\
\mathrm{g} \mathrm{kg}^{-1}\end{array}$} & \multirow{2}{*}{$\begin{array}{c}\mathrm{P} \\
\mathrm{mg} \mathrm{kg}^{-1}\end{array}$} & $\mathrm{~K}$ & $\mathrm{Ca}$ & $\mathrm{Mg}$ & $\mathrm{S}$ \\
\hline & & & & & & \multicolumn{3}{|c|}{$\mathrm{cmol}_{\mathrm{c}} \mathrm{kg}^{-1}$} \\
\hline T1 & 4,92 & 2,78 & 3,08 & 553 & 2,89 & 22,50 & 3,40 & 29,4 \\
\hline $\mathrm{T} 2$ & 4,88 & 0,61 & 1,23 & 14 & 0,67 & 1,60 & 1,00 & 3,8 \\
\hline T3 & 5,11 & 1,36 & 1,46 & 13 & 1,82 & 3,20 & 1,70 & 7,6 \\
\hline $\mathrm{T} 4$ & 4,83 & 1,79 & 2,02 & 13 & 2,35 & 4,40 & 2,80 & 10,8 \\
\hline T5 & 5,16 & 3,00 & 3,47 & 27 & 6,17 & 10,90 & 4,60 & 24,6 \\
\hline T6 & 5,32 & 4,34 & 5,88 & 33 & 3,63 & 20,60 & 15,20 & 41,5 \\
\hline
\end{tabular}

$\mathrm{T} 1=100 \%$ de substrato comercial; $\mathrm{T} 2=20 \%$ de CDB $+80 \%$ de Solo; $\mathrm{T} 3=40 \%$ de CDB $+60 \%$ de Solo; $\mathrm{T} 4=$ $60 \%$ de CDB + de $40 \%$ Solo; $55=80 \%$ de CDB $+20 \%$ de Solo; e T6= $100 \%$ de CDB.

Nas Tabelas 1 e 2 pode-se verificar a caracterização química e física dos substratos. E no solo que compõem os substratos com CDB, foi realizada análise granulométrica: $384 \mathrm{~g}$ areia grossa $/ \mathrm{kg} ; 336 \mathrm{~g}$ areia fina $/ \mathrm{kg} ; 112 \mathrm{~g}$ de silte $/ \mathrm{kg} ; 168 \mathrm{~g}$ de argila total $/ \mathrm{kg} ; 38 \mathrm{~g}$ de argila natural/kg; classificação textural Franco arenosa; e grau de floculação de 77 g/100 g.

Para determinação dos efeitos dos respectivos tratamentos na formação de mudas foram avaliadas as seguintes variáveis: i) emergência de plântulas (\%): contagem do número de plântulas emergidas diariamente até a estabilização; ii) índice de velocidade de emergência (IVE): calculado de acordo com Maguire (1962).

Cultura Agronômica, Ilha Solteira, v.26, n.3, p.406-416, 2017 
Tabela 2. Densidade global (DG), densidade de partícula (DP) e porosidade (P) do substrato comercial e dos substratos a base de caule decomposto de babaçu (CDB).

\begin{tabular}{cccc}
\hline Substratos & \multicolumn{2}{c}{ Densidade $\left(\mathrm{g} / \mathrm{cm}^{3}\right)$} & Porosidade $(\%)$ \\
& DG & DP & \\
\hline T1 & 0,56 & 0,85 & 34,43 \\
T2 & 1,28 & 2,64 & 51,53 \\
T3 & 1,18 & 2,57 & 54,01 \\
T4 & 0,98 & 2,24 & 56,22 \\
T5 & 0,73 & 1,88 & 60,91 \\
T6 & 0,33 & 0,97 & 65,95
\end{tabular}

$\mathrm{T} 1=100 \%$ de substrato comercial; $\mathrm{T} 2=20 \%$ de $\mathrm{CDB}+80 \%$ de Solo; $\mathrm{T} 3=40 \%$ de CDB $+60 \%$ de Solo; $\mathrm{T} 4=$ $60 \%$ de CDB + de $40 \%$ Solo; T5 $=80 \%$ de CDB $+20 \%$ de Solo; e T6=100\% de CDB.

Ao término do experimento, 19 (dezenove) dias após a semeadura, as plantas foram retiradas dos substratos, lavadas em água e conduzidas ao laboratório, onde foram avaliadas as variáveis: i) número de folhas; ii) altura da planta (cm); iii) diâmetro do caule (mm); iv) comprimento radicular $(\mathrm{cm})$; v) volume radicular $\left(\mathrm{cm}^{3}\right)$, segundo metodologia descrita por Basso (1999); v) massa seca de raiz e da parte aérea (g): obtidos pelo método da secagem em estufa com circulação forçada de ar à temperatura de $65^{\circ} \mathrm{C}$ até atingir massa constante. Determinou-se ainda o índice de qualidade de Dickson (IQD), por meio da fórmula (DICKSON et al., 1960):

$$
\mathrm{IQD}=\frac{\mathrm{MST}(\mathrm{g})}{\mathrm{AP}(\mathrm{cm}) / \mathrm{DC}(\mathrm{mm})+\operatorname{MSPA}(\mathrm{g}) / \operatorname{MSR}(\mathrm{g})}
$$

Os dados foram submetidos à análise de variância pelo teste " $F$ ", para diagnóstico de efeito significativo, e os tratamentos comparados entre si pelo teste Tukey a $5 \%$ de probabilidade, através do programa computacional Assistat ${ }^{\circledR}$.

\section{RESULTADOS E DISCUSSÃO}

A G\% e o IVE não apresentaram diferença estatística entre os tratamentos ao utilizar diferentes proporções de caule decomposto de babaçu (CDB) na produção de mudas de melancieira 'Crimson Sweet', como é demostrado na Tabela 3, mas ambos demonstraram melhor resultados, numericamente, em substratos com 100\% de CDB, 61,45\% e 14,16, respectivamente.

Os valores de G\% encontrados na Tabela 3 são inferiores ao obtido por Mota et al. (2011), que verificou porcentagem de germinação acima de $90 \%$, caso que não correu neste presente trabalho.

Duarte et al. (2010), encontraram resultados semelhantes do IVE (Tabela 3), atingindo o valor de 13,56, quando utilizou esterco de galinha, ao estudar o aumento das doses de esterco de galinha adicionado ao substrato. entretanto esse estudo é considerado inferior ao apresentando neste trabalho. Isto pode ter ocorrido em função das características físicas do 
$\mathrm{CDB}$, que promove adequada germinação das mudas, devido à capacidade de retenção de umidade do substrato e consequentemente o fornecimento de condições ideais para a embebição das sementes.

Tabela 3. Resumo da análise de variância da Porcentagem de Emergência (G) e Índice de Velocidade de Emergência (IVE) de mudas de melancieira em função de diferentes substratos a base de caule decomposto de babaçu.

\begin{tabular}{ccc}
\hline Fonte de Variação & G\% & IVE \\
\cline { 2 - 3 } & $\% \bar{c}$ \\
\hline Tratamento & $1,27 \mathrm{~ns}$ & $0,44 \mathrm{~ns}$ \\
Repetição & 37,18 & 1,70 \\
Resíduo & 29,17 & 3,79 \\
\hline T1 & $65,93 \mathrm{a}$ & $12,73 \mathrm{a}$ \\
T2 & $58,85 \mathrm{a}$ & $13,04 \mathrm{a}$ \\
T3 & $53,64 \mathrm{a}$ & $12,33 \mathrm{a}$ \\
T4 & $60,93 \mathrm{a}$ & $13,34 \mathrm{a}$ \\
T5 & $61,45 \mathrm{a}$ & $13,63 \mathrm{a}$ \\
T6 & $61,45 \mathrm{a}$ & $14,16 \mathrm{a}$ \\
\hline DMS & 12,12 & 4,37 \\
\hline C.V. & 9,07 & 14,74
\end{tabular}

$\mathrm{T} 1=100 \%$ de substrato comercial; $\mathrm{T} 2=20 \%$ de $\mathrm{CDB}+80 \%$ de Solo; $\mathrm{T} 3=40 \%$ de CDB $+60 \%$ de Solo; $44=$ $60 \%$ de CDB + 40\% de Solo; T5= 80\% de CDB + 20\% de Solo; T6= 100\% de CDB; DMS: diferença mínima significativa; CV: coeficiente de variação; **: Significativo ao nível de $1 \%$ de probabilidade, pelo teste F; *: Significativo ao nível de 5\% de probabilidade, pelo teste F; ns: não significativo.

Tais resultados, tanto para emergência quanto para IVE, podem ser atribuídas à possível capacidade do material de manter água nas proximidades das sementes, características desejáveis no intuito de se obter uniformidade na emergência (CARVALHO; NAKAGAWA, 2000).

A utilização de diferentes proporções de caule decomposto de babaçu (CDB) na produção de mudas de melancieira 'Crimson Sweet' em comparação ao substrato comercial proporcionou um efeito significativo $(\mathrm{p}<0,05)$, pelo teste $\mathrm{F}$ a diâmetro do caule (DC) e massa seca da parte aérea (MSPA), e um efeito significativo ( $p<0,01)$, para o número de folhas $(\mathrm{NF})$ e a altura da planta (AP), como apresentado na Tabela 4.

Ao que se refere ao número de folhas (Tabela 4), os maiores valores médio observados foi de 4,00 e 3,82 unidades planta ${ }^{-1}$ no $\mathrm{T} 1$ e T6, respectivamente, diferente do T2 composto por $20 \%$ de CDB que apresentou o menor resultando, 3,34 unidades planta ${ }^{-1}$, sendo este resultado considerado adequado pelo proposto por Belfort e Gomes (2000), que ao estudar o momento ideal de transplante de mudas de melancia recomendaram que estas devessem apresentar de 3 a 4 folhas definitivas.

Cultura Agronômica, Ilha Solteira, v.26, n.3, p.406-416, 2017 
Mota et al. (2011), ao estudar desenvolvimento inicial de mudas de melancieira 'Crimson Sweet' irrigadas com águas residuárias, obteviveram 3,25, sendo esta ainda inferior quando comparada a T2 com apenas $20 \%$ de CDB do presente trabalho.

Tabela 4. Resumo da análise de variância do número de folhas (NF), altura da planta (AP), diâmetro do caule (DC) e massa seca da parte aérea (MSPA) de mudas de melancieira 'Crimson Sweet' produzidas com substratos com diferentes proporções de caule decomposto de babaçu (CDB).

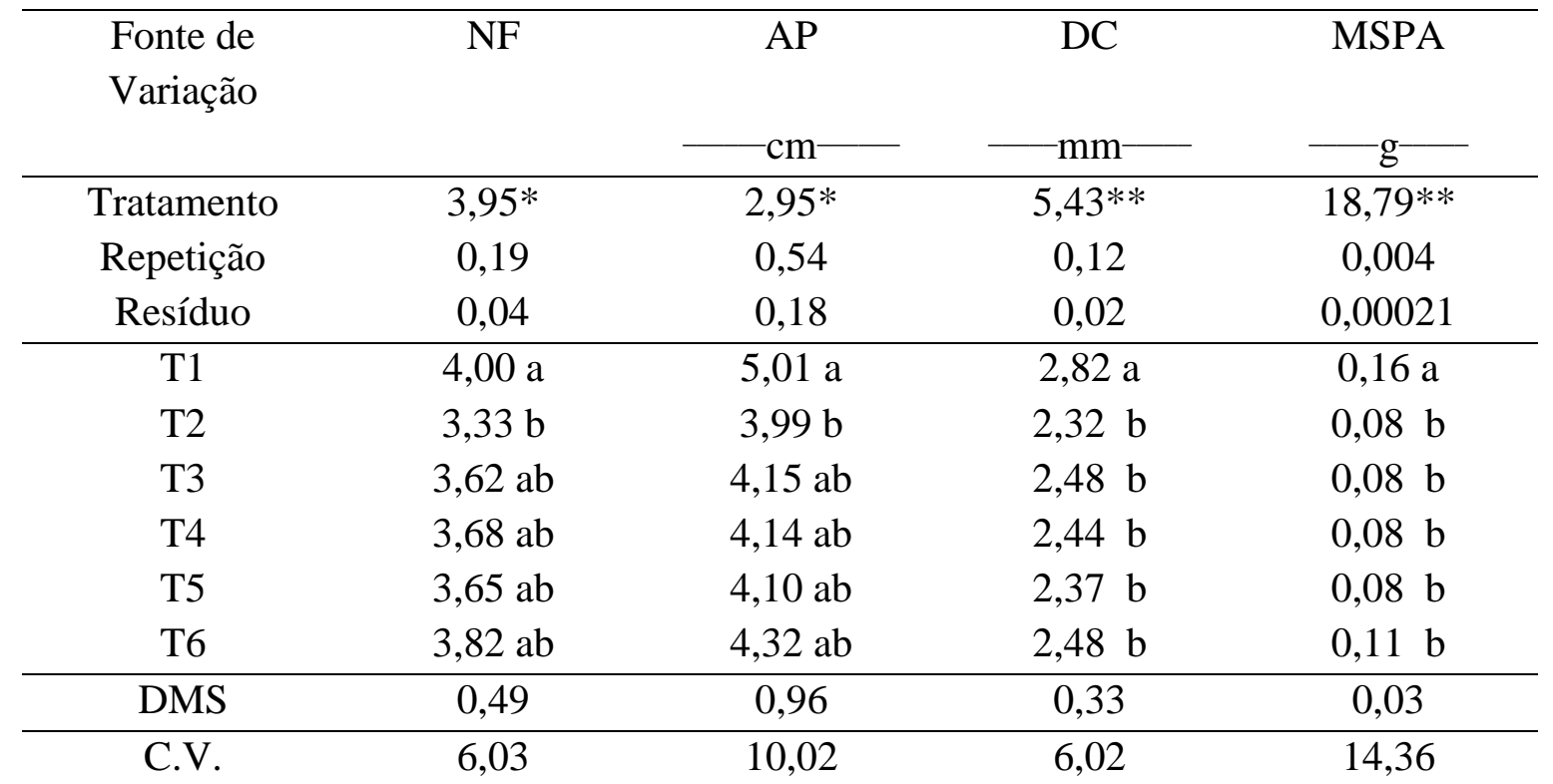

$\mathrm{T} 1=100 \%$ de substrato comercial; $\mathrm{T} 2=20 \%$ de $\mathrm{CDB}+80 \%$ de Solo; $\mathrm{T} 3=40 \%$ de CDB $+60 \%$ de Solo; $\mathrm{T} 4=$ $60 \%$ de CDB $+40 \%$ de Solo; T5= 80\% de CDB + 20\% de Solo; T6= 100\% de CDB; DMS: diferença mínima significativa; CV: coeficiente de variação; **: Significativo ao nível de $1 \%$ de probabilidade, pelo teste F; *: Significativo ao nível de 5\% de probabilidade, pelo teste F; ns: não significativo.

De acordo com Ferreira et al. (2005), a taxa de crescimento das folhas é diretamente influenciada pelo suprimento de nitrogênio, entendendo que o mesmo é um dos fatores determinantes da taxa de acúmulo de biomassa. Desta forma, é possível afirmar que, o caule decomposto de babaçu contribuiu como fonte de nitrogênio para o substrato gradativamente à medida que aumentava as proporções de CDB, no qual T6 (100\% CDB) apresentou 5,88 g $\mathrm{Kg}^{-1}$ de nitrogênio, 79,08\% a mais quando comparado ao T2 (20\% CDB) (Tabela 1).

A variável altura da planta (Tabela 4) demonstrou melhor resultado na testemunha, obtendo 5,1 cm, entretanto, os tratamentos os demais tratamentos contendo CDB, demonstraram maior resultado quando comprado com a média obtida por Dalastra et al. (2016), com apenas $3,30 \mathrm{~cm}$.

Em geral, é possível perceber que ouve uma relação entre o número de folhas e a altura da planta, no que se refere a possível maior disponibilidade de área foliar como consequência do maior número de folhas. Com o aumento do número de folhas as plantas obtêm maior taxa de assimilação de luz e possibilidade de realização de fotossíntese com consequente maior altura (MELO et al., 2007). 
Quanto ao diâmetro (Tabela 4), houve um maior incremento em plântulas que utilizaram o substrato comercial para a formação de mudas com $2,82 \mathrm{~mm}$, assim, diferindo dos demais tratamentos que continham CDB.

Conforme Kozlowski (1962) a fotossíntese, aparentemente, guarda uma relação mais direta com o crescimento em diâmetro do que em altura de plântulas, na qual o autor considerou que a quantidade de fotoassimilados e reguladores de crescimento estão ligados diretamente ao aumento do diâmetro do coleto.

Em relação a variável massa seca da parte aérea (MSPA) representada na Tabela 4, foi averiguado que entre os tratamentos com CDB, o T6 apresentou numericamente incremento na matéria seca em comparação aos outros tratamentos contendo $\mathrm{CDB}$, apesar de não apresentar diferenças entre estes, sendo apenas inferior ao substrato comercial. Fato que pode ser explicado pelos maiores teores de $\mathrm{N}$ e $\mathrm{K}$ encontrados nos substratos com maiores quantidades de $\mathrm{CDB}$, além do substrato comercial. Por outro lado, o nitrogênio e o fósforo, quando utilizados juntos, interagem positivamente para aumentar a matéria seca das plantas (MAPELI et al., 2005), desta forma, pode-se também destacar o alto conteúdo no composto com $100 \%$ de caule decomposto, $47,61 \%$ a mais do que o substrato comercial, que por outro lado, este apresentou maior conteúdo de fósforo.

De acordo com Grangeiro e Cecílio Filho (2004) esses nutrientes desempenham importantes funções no desenvolvimento inicial da muda, pois estimulam tanto o crescimento das raízes como também da parte aérea, e em se tratando da cultura da melancia o potássio e o nitrogênio são também os nutrientes mais exigidos ao longo do ciclo de cultivo.

A utilização de diferentes proporções de caule decomposto de babaçu (CDB) na produção de mudas de melancieira 'Crimson Sweet' em comparação ao substrato comercial proporcionou um efeito significativo ( $\mathrm{p}<0,05$ ), pelo teste $\mathrm{F}$ em relação ao sistema radicular apenas no comprimento radicular (CR), mas não apresentou diferença significativa ao volume radicular (VR), massa seca do sistema radicular (MSSR) e ao índice de qualidade de Dickson (IQD) (Tabela 5).

Para a variável CR, é possível observar na Tabela 5, que os melhores resultados foram obtidos no T3, T4, T5 e T6, observando uma redução ao utilizar o T1 e o T2.

Os resultados deste trabalho foram ainda superiores aos reportados por Silva e Ferreira (2015) ao avaliarem o desenvolvimento de mudas de melancia sob efeitos substratos, no qual obteve comprimento médio de $5,51 \mathrm{~cm}$ ao utilizar o substrato comercial Plantmax ${ }^{\circledR}$, constatado s 40,87\% inferior ao encontrado na proporção de $100 \% \mathrm{CDB}$, em função disso, observa-se a importância da utilização de substratos orgânicos no desenvolvimento de mudas de melancieira. O comprimento das raízes relacionado com altura de plantas são fatores que definem a qualidade e resistência das mudas quando forem transplantadas no campo, sendo que plantas mal desenvolvidas podem proporcionar baixa produção (SILVA et al., 2016).

Cultura Agronômica, Ilha Solteira, v.26, n.3, p.406-416, 2017 
Tabela 5. Resumo da análise de variância do comprimento radicular (CR), volume radicular (VR), massa seca do sistema radicular (MSSR) e índice de qualidade de Dickson (IQD) de mudas de melancieira 'Crimson Sweet' produzidas com substratos com diferentes proporções de caule decomposto de babaçu (CDB).

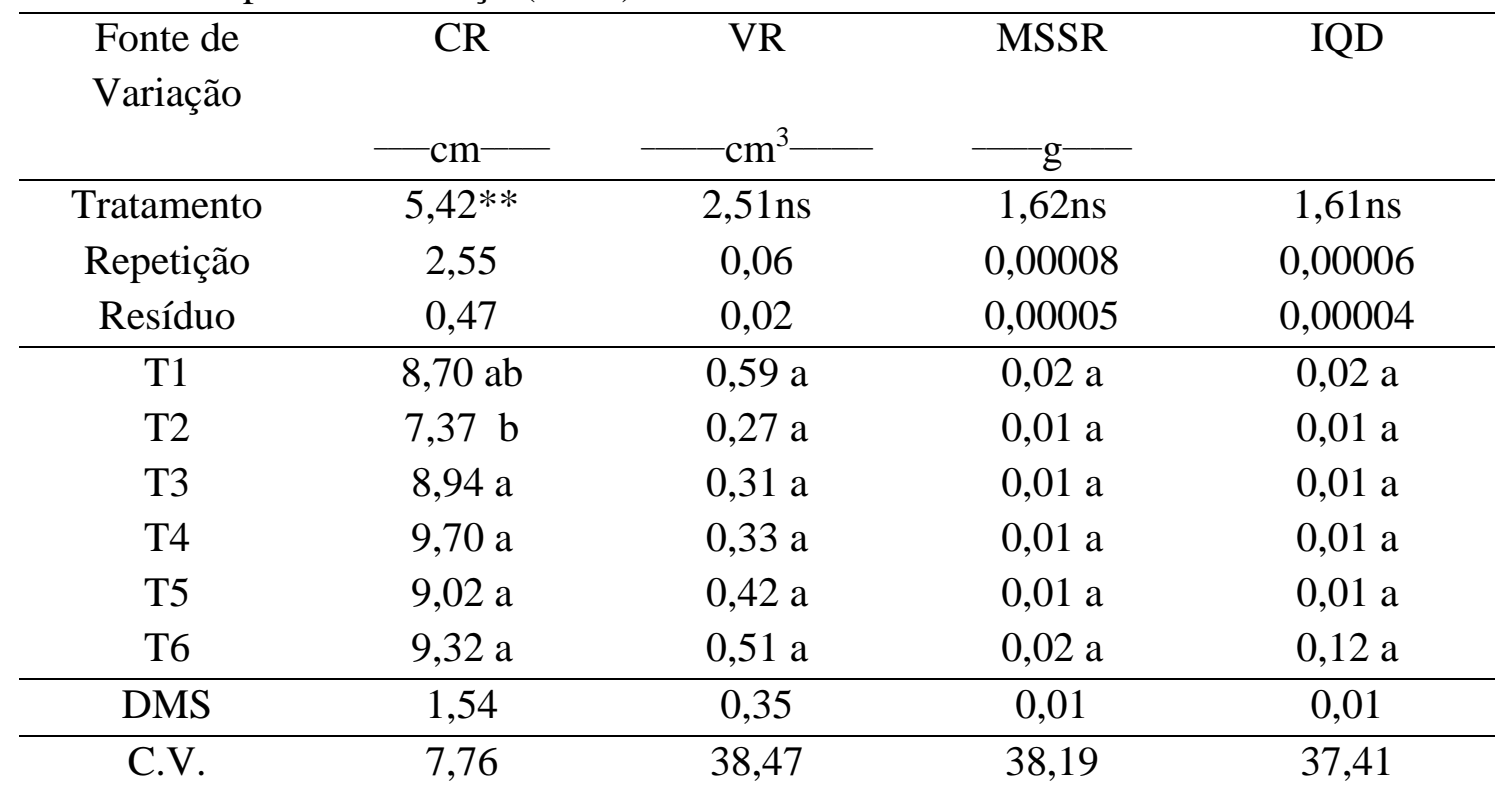

$\mathrm{T} 1=100 \%$ de substrato comercial; $\mathrm{T} 2=20 \%$ de $\mathrm{CDB}+80 \%$ de Solo; $\mathrm{T} 3=40 \%$ de CDB $+60 \%$ de Solo; $44=$ $60 \%$ de CDB $+40 \%$ de Solo; T5= 80\% de CDB + 20\% de Solo; T6= 100\% de CDB; DMS: diferença mínima significativa; CV: coeficiente de variação; **: Significativo ao nível de $1 \%$ de probabilidade, pelo teste $\mathrm{F}$; *: Significativo ao nível de 5\% de probabilidade, pelo teste F; ns: não significativo.

Quanto ao volume radicular (Figura 3B), não houve diferença significa entre os tratamentos, mas foi obtido aumento numérico no incremento do volume radicular à medida que aumentava a proporção de CDB na produção de mudas.

De acordo com Hartmann et al. (2002), o sistema radicular só se desenvolve satisfatoriamente quando o substrato combina boa aeração com alta capacidade de retenção de água, boa drenagem e ausência de contaminantes, o que em consequência gera um bom desenvolvimento da parte aérea.

Ao avaliar o incremento da massa seca do sistema radicular nas mudas de melancieira apresentada na Tabela 5, foi averiguado que esta variável não foi afetada pelas diferentes proporções de CDB e substrato comercial, em que dentre estes o T6 (100\% CDB) demonstrou valor numérico maior em relação ao T1 (substrato comercial), correspondendo a 0,022 g e $0,025 \mathrm{~g}$, respectivamente. Esses resultados caracterizam redução de $0,07 \mathrm{~g}$ ao obtido por Oliveira et al. (2015).

O peso da matéria seca das raízes tem sido reconhecido por diferentes autores, como sendo um dos mais importantes e melhores parâmetros para se estimar a sobrevivência e o crescimento inicial das mudas no campo (GOMES, 2001). 
É possível observar que não houve diferença significativa entre os tratamentos para o IQD (Tabela 5), destacando numericamente o maior resultado obtido na muda com $100 \%$ de CDB $(0,022)$, sendo este valor superior ao encontrado por Oliveira et al. (2015) ao estudar a produção de mudas de melancia da cv. Crimson Sweet em diferentes ambientes, especialmente, sob sombrite $(0,013)$ e aluminet $(0,014)$, mas inferior ao valor encontrado sob estufa $(0,025)$. o mesmo autor ainda ressalta que o IQD é um bom indicador de qualidade de mudas de melancia, pois abrange diversas características

\section{CONCLUSÃO}

O substrato com caule decomposto de babaçu apresenta resultados satisfatórios, podendo substituir o substrato comercial, além de ser de fácil obtenção e baixo custo, sendo alternativa viável aos produtores rurais na produção de mudas de melancieira.

\section{REFERÊNCIAS BIBLIOGRÁFICAS}

ALMEIDA, E. I. B.; CORRÊA, M. C. M.; NÓBREGA, G. N.: PINHEIRO, E. A. R.; LIMA, F. F. Crescimento e marcha de absorção de macronutrientes para a cultivar de melancia Crimson Sweet. Revista Agro@mbiente, Roraima, v. 6, n. 3, p.205-214, 2012.

BASSO, C. J. Épocas de aplicação de nitrogênio para o milho cultivado em sucessão a plantas de cobertura de solo, no sistema plantio direto. 1999. $91 \mathrm{f}$. Tese (Mestrado em Agronomia) - Universidade Federal de Santa Maria, Santa Maria, 1999.

BELFORT, C. C.; GOMES, M. S. F. D. Avaliação da idade de transplantio para mudas de melancia. Horticultura Brasileira, Brasília, v. 18, supl., p.468-469, 2000.

CARVALHO, N. M.; NAKAGAWA, J. Sementes: ciência tecnologia e produção. 4. ed. Jaboticabal: FUNEP, 2000. $580 \mathrm{p}$.

COÊLHO, J. L. S.; SILVA, R. M.; BAIMA, W. D. S.; GONSALVES, H. R. O.; NETO, F. C. S.; AGUIAR, A. V. M. Diferentes substratos na produção de mudas de pimentão. Agropecuária Científica no Semiárido, Campina Grande, v. 9, n. 2, p.01-04, 2013.

COSTA, C. L. L.; COSTA, Z. V. B.; JÚNIOR, C. O. C.; ANDRADE, J.; SANTOS, J. G. R. Utilização de bioestimulante na produção de mudas de melancia. Revista Verde de Agroecologia e Desenvolvimento Sustentável, Mossoró, v. 3, n. 3, p.110-115, 2008.

COSTA, K. D. S.; CARVALHO, I. D. E.; FERREIRA, P. V.; SILVA, J.; TEIXEIRA, J. S. Avaliação de substratos alternativos para a produção de mudas de alface. Revista Verde, Mossoró, v. 7, n. 5, p.58-62, 2012.

DALASTRA, G. M.; ECHER, M. M.; HACHMANN, T. L.; GUIMARÃES, V. F.; SCHMIDT, M. H.; CORBARI, F. L. Desenvolvimento e produtividade da melancia em

Cultura Agronômica, Ilha Solteira, v.26, n.3, p.406-416, 2017 
função do método de cultivo. Brazilian journal of agriculture - Revista de Agricultura, Piracicaba, v. 91, n. 1, p.54-66, 2016.

DICKSON, A.; LEAF, A. L.; HOSNER, J. F. Quality appraisal of white spruce and white pine seedling stock in nurseries. The Forestry Chronicle, Canadá, v. 36, n. 1, p.10-13, 1960.

DUARTE, A. K. A.; CARDOSO, M. O.; FIGUEIREDO, L. Crescimento e macronutrientes em mudas de melancia com doses de adubo orgânico. Horticultura Brasileira, Brasília, v. 28, n. 2, p.1633-1638, 2010.

DUTRA, T. R.; MASSAD, M. D.; SARMENTO, M. F. Q.; OLIVEIRA, J. C. Emergência e crescimento inicial da canafístula em diferentes substratos e métodos de superação de dormência. Revista Caatinga, Mossoró, v. 25, n. 2, p.65-71, 2012.

FERREIRA, O. E.; BELTRÃO, N. E. M.; KONIG, A. Efeitos da aplicação de água residuária e nitrogênio sobre o crescimento e produção do algodão herbáceo. Revista Brasileira de Oleaginosas e Fibrosas, Campina Grande, v. 9, n. 1, p.893-902, 2005.

FERREIRA, P. V. Estatística experimental aplicada à Agronomia. 3. ed. Maceió: UFAL, 2000. 604 p.

GOMES, J. M. Parâmetros morfológicos na avaliação da qualidade de mudas de Eucalyptus grandis, produzidas em diferentes tamanhos de tubete e de dosagens de N-PK. 2001. 126 f. Tese (Doutorado em Ciência Florestal) - Universidade Federal de Viçosa, Viçosa, 2001.

GRANGEIRO, L. C.; CECÍlIO FILHO, A. B. Acúmulo e exportação de macronutrientes pelo híbrido de melancia Tide. Horticultura Brasileira, Brasília, v. 22, n. 1, p.93-97, 2004.

HARTMANN, H. T.; KESTER, D. E.; DAVIES, J. F. T.; GENEVE, R. L. Plant Propagation: Principles and Practices. 7. ed. New York: Englewood Clipps, 2002. 880 p.

IBGE. INSTITUTO BRASILEIRO DE GEOGRAFIA E ESTATISTICA. Disponível em: www.sidra.ibge.gov.br . Acesso em: 27 jun. 2014.

KOZLOWSKI, T. T. (ed.). Photosynthesis, climate and tree growth. In: Tree growth. New York: The Ronald Press, 1962. cap. 8, p. 149-170.

MAGGIONI, M. S.; ROSA, C. B. C. J.; ROSA JUNIOR, E. J.; SILVA, E. F.; ROSA, Y. B. C. J.; SCALON, S. P. Q.; VASCONCELOS, A. A. Development of basil seedlings (Ocimum basilicum L.) in different density and type of substrates and trays. Revista Brasileira de Plantas Medicinais, Paulínia, v. 16, n. 1, p.10-17, 2014.

MAGUIRE, J. D. Speed of germination aid in selection and evaluation for seedling emergence and vigor. Crop Science, Madison, v. 2, n. 2, p.176-177, 1962.

MAPELI, N. C.; VIEIRA, M. C.; HEREDIA, Z.; NESTOR, A.; SIQUEIRA, J. M. Produção de biomassa e de óleo essencial dos capítulos florais da camomila em função do nitrogênio e fósforo. Horticultura Brasileira, Brasília, v. 23, n. 1, p.32-37, 2005.

Cultura Agronômica, Ilha Solteira, v.26, n.3, p.406-416, 2017 
MARTINS, W. M. O.; PAIVA, F. S.; BANTEL, C. A. Produção orgânica de mudas de Cucumis sativus com substratos alternativos. Enciclopédia Biosfera, Goiânia, v. 9, n. 16, p.1799-1805, 2013.

MELO, A. S.; COSTA, C. X.; BRITO, M. E. B.; VIÉGAS, P. R. A.; SILVA JÚNIOR, C. D. Produção de mudas de mamoeiro em diferentes substratos e doses de fósforo. Revista Brasileira de Ciências Agrárias, Recife, v. 2, n. 4, p.257-261, 2007.

MOTA, A. F.; ALMEIDA, J. P. N.; SOUSA. J.; AZEVEDO, J.; GURGEL, M. T. Desenvolvimento inicial de mudas de melancia 'Crimson Sweet' irrigadas com águas residuárias. Revista Verde de Agroecologia e Desenvolvimento Sustentável, Mossoró, v. 6, n. 2, p.98-104, 2011.

OLIVEIRA, A. M. D.; COSTA, E.; REGO, N. H.; LUQUI, L. de L.; KUSANO, D.M.; OLIVEIRA, E. P. Produção de mudas de melancia em diferentes ambientes e de frutos a campo. Revista Ceres, Viçosa, v. 62, n. 1, p.87-92, 2015.

ROCHA, M. R. Sistemas de cultivo para a cultura da melancia. 2010. 76 f. Dissertação (Mestrado em Agronomia) - Universidade Federal de Santa Maria, Santa Maria, 2010.

SILVA, L. R.; FERREIRA L. G. Desenvolvimento de mudas de melancia sob efeitos de diferentes tipos de bandejas e substratos. Connection Line, Várzea Grande, v. 10, n. 12, p. 97-105, 2015.

SILVA, M. R. R.; VANZELA, L. S.; PINHEIRO, L. C.; SANTOS SOUZA, J. F. Efeito de diferentes compostos na produção de mudas de mamoeiro. Nucleus, Ituverava, v. 13, n. 1, p.63-70, 2016.

SILVA-MATOS, R. R. S.; CAVALCANTE, Í. H. L.; SILVA JUNIOR, G. B.; ALBANO, F. G.; CUNHA M. S.; BECKMANN-CAVALCANTE, M. Z. Foliar spray of humic substances on seedling production of watermelon cv. Crimson Sweet. Journal of Agronomy, Faisalabad, v. 11, n. 2, p.60-64, 2012. 